DOI: 10.12731/2658-6649-2020-12-2-89-92

УДК 616.12

\title{
ОСОБЕННОСТИ ТЕЧЕНИЯ СЕРДЕЧНОЙ НЕДОСТАТОЧНОСТИ У БОЛЬНЫХ ПОЖИЛОГО И СТАРЧЕСКОГО ВОЗРАСТА
}

\section{Павлова Н.И., Кожсевникова А.Д., Жданов Г.Н., Ягункина О.Г.}

Изучена этиология, особенности клинической картины и тяжести течения сердечной недостаточности, причины ее прогрессирования у больных пожилого и старческого возраста. Дана оченка качества и эффективности проводимой амбулаторно терапии. Показано, что пациентам данной категории свойственна высокая коморбидность и сердечная недостаточность у них имеет многофакторный характер, что затрудняет выбор оптимальной и безопасной терапии. Основными причинами декомпенсаџии являются неадекватная терапия, девиация доз лекарственных препаратов и отсутствие приверженности больных клечению.

Ключевые слова: кардио-гериатрический синдром; сердечная недостаточность; коморбидность; ишемическая болезнь сердиа; артериальная гипертония; фибриллячия предсердий; эхокардиография.

\section{FEATURES OF THE COURSE OF HEART FAILURE IN ELDERLY AND SENILE PATIENTS}

\section{Pavlova N.I., Kozhevnikova A.D., Zhdanov G.N., Yagunkina O.G.}

The etiology, features of the clinical picture and severity of heart failure, the causes of its progression in elderly and senile patients were studied. The quality and effectiveness of outpatient therapy is evaluated. It is shown that patients in this category are characterized by high comorbidity and heart failure has a multifactorial character, which makes it difficult to choose the optimal and safe therapy. The main causes of decompensation are inadequate therapy, deviation of drug doses and lack of adherence of patients to treatment.

Keywords: cardio-geriatric syndrome; heart failure; comorbidity; ischemic heart disease; arterial hypertension; atrial fibrillation; echocardiography. 
Возраст является важнейшим фактором риска развития сердечной недостаточности $(\mathrm{CH})$. Известно, что в общей популяции распространенность $\mathrm{CH}$ составляет 2\%, тогда как у лиц старше 65 лет она достигает $15 \%$. СН в 21 веке является кардио-гериатрическим синдромом. Она связана с плохим прогнозом для жизни. Риск внезапной смерти у больных в 5 раз выше, чем в популяции, а пятилетняя выживаемость меньше $50 \%(1,2,3,4)$.

\section{Цель исследования}

Изучение этиологии, особенностей клинической картины, тяжести течения сердечной недостаточности, причин госпитализации больных с данной патологией, а также оценка качества и эффективности проводимой амбулаторно терапии у лиц пожилого и старческого возраста.

\section{Материалы и методы}

Обследовано 30 мужчин и 25 женщин в возрасте 65-85 лет с СН 2A2Б стадии, II-Ш ФК (NYHA) и длительностью заболевания от года до 5 лет. У всех больных помимо клинического обследования, анализировали показатели крови, электрокардиограммы и эхокардиографии.

\section{Результаты}

Установлено, что основной причиной развития СН была ишемическая болезнь сердца(ИБС), постинфарктный кардиосклероз(ПИКС) у - 33 (60\%) пациентов. Гипертоническая и ишемическая болезни выявлены у -14 (25\%), сочетание ИБС, артериальной гипертонии и фибрилляции предсердий обнаружено у шести пациентов (10\%). У одного больного диагносцирована хроническая обструктивная болезнь легких с декомпенсированным легочным сердцем, еще один имел аортальный порок сердца. Среди ассоциированных заболеваний наиболее часто встречались сахарный диабет и ожирение (ИМТ $>30$ ). Обычно возрастные пациенты жаловались на сухой кашель, особенно в горизонтальном положении и ночью, а также после физической нагрузки, одышку, отеки, слабость и выраженную усталость. На ЭКГ у них выявлялись рубцовые изменения миокарда, нарушения ритма по типу экстрасистолии и фибрилляции предсердий, а также внутрижелудочковые блокады, чаще левой ножки пучка Гиса. По данным эхокардиографии фракция выброса левого желудочка была снижена у всех больных и составляла от 45 до 30\%. У половины пациентов выявлена легочная гипертензия (45-50 мм.рт.ст.). Ретроспективный анализ амбулаторных медицинских карт и данные анамнеза свидетельствовали о том, что регулярно принимали адекватную комплексную 
терапию только 17 (30\%) больных. При этом основной причиной госпитализации у большинства пациентов явилось прогрессирование СН. В стационаре на фоне терапии, включавшей ингибиторы АПФ или блокаторы рецепторов ангиотензина, антагонисты альдостерона, $\beta$-адреноблокаторы, сердечные гликозиды и диуретики, состояние большинства больных улучшилось. Выписаны с индивидуальными рекомендациями под наблюдение участкового врача.

\section{Выводы}

Таким образом, у пациентов старших возрастных групп наиболее частыми причинами сердечной недостаточности являются ишемическая болезнь сердца, постинфарктный кардиосклероз, артериальная гипертония и фибрилляция предсердий. Больным пожилого и старческого возраста свойственна высокая коморбидность. Сердечная недостаточность у них имеет многофакторный характер, что затрудняет выбор оптимальной и безопасной терапии. Основными причинами декомпенсации были неадекватная терапия, девиация доз лекарственных препаратов, а также отсутствие приверженности больных к лечению.

\section{Список литературы}

1. Практическая гериатрия (избранные клинические и организационные аспекты) / Под редакцией проф. Л.Б. Лазебника. Москва, 2002. С. 141-150.

2. Провоторов В.М., Бурлова Е.С. Диагностика хронической сердечной недостаточности на ранних стадиях у лиц пожилого возраста//Клиническая геронтология. 2007, т.13, №6. С. 57-62.

3. Берштейн Л.Л., Новиков В.И., Гришкин Ю.Н. Пожилой возраст как фактор риска развития сердечной недостаточности после острого инфаркта миокарда // Успехи геронтологии. 2008, т.21, №2. С. 265-269.

4. Лазебник Л.Б., Конев Ю.В., Ефремов Л.И. Основная проблема гериатрии множественность болезней у пожилого больного // Клиническая геронтология. 2019, №1-2. С. 4-9.

\section{References}

1. Prakticheskaya geriatriya (izbrannye klinicheskie i organizatsionnye aspekty) [Practical geriatrics (selected clinical and organizational aspects)] / Ed. prof. L.B. Lazebnik. Moscow, 2002, pp. 141-150.

2. Provotorov V.M., Burlova E.S. Klinicheskaya gerontologiya. 2007, V.13, №6, pp. 57-62.

3. Bershteyn L.L., Novikov V.I., Grishkin Yu.N. Uspekhi gerontologii. 2008, V.21, №2, pp. 265-269. 
4. Lazebnik L.B., Konev Yu.V., Efremov L.I. Klinicheskaya gerontologiya. 2019, №1-2, pp. 4-9.

\section{ДАННЫЕ ОБ АВТОРАХ}

Павлова Наталья Ивановна, кандидат медицинских наук Тверской государственный медииинский университет ул. Советская, 4, г. Тверь, 170100, Российская Федерация natnicpav@gmail.com

Кожевникова Александра Дмитриевна, заведующая терапевтическим отделением ЧУЗ «КБ «РЖД-Медииина» г.Тверь» ул. Арсения Степанова, 2а, г. Тверь, 170001, Российская Федерация

Жданов Геннадий Николаевич, заместитель главного врача по лечебной работе

ЧУЗ «КБ «РЖД-Медицина» г.Тверь»

ул. Арсения Степанова, 2а, г. Тверь, 170001, Российская Федеращия

Ягункина Ольга Геннадьевна, заведующая дневным стационаром ЧУЗ «КБ «РЖД-Медииина» г.Тверь» ул. Арсения Степанова, 2a, г. Тверь, 170001, Российская Федераџия

\section{DATA ABOUT THE AUTHORS}

Pavlova Natalya Ivanovna, candidate of medical sciences Tver State Medical University 4, Sovetskaya Str., Tver, 170100, Russian Federation natnicpav@gmail.com

Kozhevnikova Alexandra Dmitrievna, head of the therapeutic department Clinical Hospital Russian Railways-Medicine, Tver 2a, Arseniy Stepanov Str., Tver, 170001, Russian Federation

Zhdanov Gennady Nikolaevich, deputy chief physician for medical work Clinical Hospital Russian Railways-Medicine, Tver 2a, Arseniy Stepanov Str., Tver, 170001, Russian Federation

Yagunkina Olga Gennadievna, head of the day hospital Clinical Hospital Russian Railways-Medicine, Tver 2a, Arseniy Stepanov Str., Tver, 170001, Russian Federation 